\title{
ADVANCED COLLIMATOR SYSTEMS FOR THE NLC
}

\author{
Josef Frisch ,Eric Doyle, Knut Skarpaas VIII SLAC, Stanford CA, 94305*
}

\section{Abstract}

The Next Linear Collider accelerator will include a large (kilometer scale) and complex collimation system. Its size and complexity could be reduced if the collimator jaws were made immune to damage from the electron beam. We describe two collimation systems currently under development. Construction of a prototype system, which uses wheels that can be moved to a new position after damage, is underway. The second system, currently in the $\mathrm{R}+\mathrm{D}$ phase, will use rotors that are continuously reformed from a bath of liquid metal as the collimation surface. This second system should allow operation at beam intensities that damage the jaws on every pulse. We describe results of tests on both systems.

\section{NLC COLLIMATION SYSTEM REQUIREMENTS}

The NLC requires collimation both before and after the main linacs. The post linac collimators in particular are technically challenging as the beam intensities and small spot sizes are sufficient to damage any solid material. Designs that avoid damage by increasing the beam size in the collimation section result in a very long system length and a very sensitive optical design. We base the engineering designs here on a beam optics design that provides reasonable tolerances, but may result in collimator surface damage. .

Table 1: NLC beam parameters in the Collimation Section

\begin{tabular}{|l|c|}
\hline \multicolumn{1}{|c|}{ Parameter } & Value \\
\hline Beam Energy & $500 \mathrm{GeV}$ \\
\hline Bunch Charge & $1.4 \times 10^{10}$ \\
\hline Beam Emittance (normalized) & $300 \times 310^{-8} \mathrm{~m}$ \\
\hline Spot Size & $50 \times 5 \mu \mathrm{m}$ \\
\hline Bunch Length & $145 \mu \mathrm{m}$ \\
\hline Number of Bunches & 95 \\
\hline Peak Current & $\sim 1200 \mathrm{~A}$ \\
\hline Required Edge Stability & $\sim 5 \mu \mathrm{m}$ \\
\hline Required surface roughness & $<1 \mu \mathrm{m} \mathrm{RMS}$ \\
\hline Collimator Gap (half gap) & $\sim 100 \mu \mathrm{m}$ \\
\hline
\end{tabular}

\section{DAMAGE MECHANISMS}

Beam damage in materials results from melting and vaporization due to energy deposition. In addition, if the thermal stress caused by the temperature rise exceeds the yield strength (or fatigue strength for multiple shots) of the material, damage can also occur.

\subsection{Electromagnetic Shower Damage}

This is the most serious source of damage in most highenergy accelerators. For each incident particle that intercepts the collimator surface, an electromagnetic cascade of particles is created over a depth of several radiation lengths. For the NLC beam parameters, peak materials temperatures of $>10^{5} \mathrm{C}$ would be created at the peak of such a shower. We plan to avoid this damage mechanism by using a combination "spoiler" and "absorber" collimation scheme. The spoiler is a thin $(\sim 1 / 2$ radiation length) object that produces a large transverse momentum spread in intercepted particles. Downstream optics are used to convert the transverse momentum spread to a large radial spread where a larger radius absorber can be used.

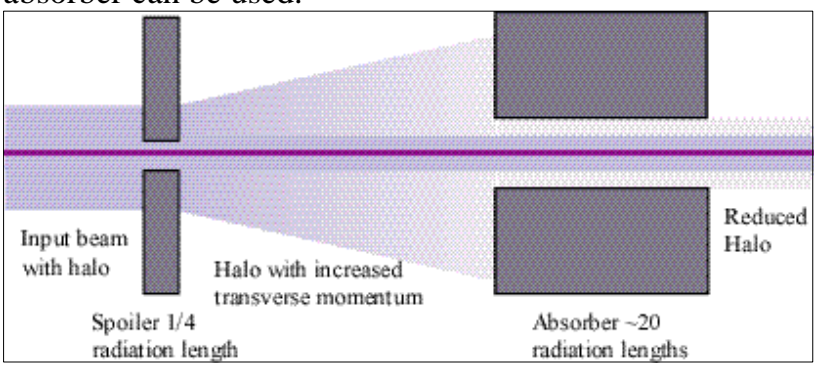

Figure 1: Spoiler / Absorber Combination

\subsection{Direct Lionization Damage}

Even without showering, the direct lionization loss of high-energy particles is sufficient to destroy any material a nominal beam size and intensity. However, under normal operating conditions, only the beam halo will be intercepted, and the collimator should not be damaged.

\subsection{Collective Damage}

The high peak currents in the NLC can produce damage from collective beam effects, even without beam interception. Image current heating and collective electric field lionization can both be significant damage sources when the collimator gaps are $<100 \mu \mathrm{m}$ full gap.[1].

\section{DAMAGE RESISTANT COLLIMATOR TECHNOLOGY}

\subsection{Consumable Collimators}

These are collimators where the jaws can be moved to a new position a finite number of times ( 1000) after being damaged by the beam. They are suitable for use under conditions where damage will occur on occasional errant

\footnotetext{
* Work Supported by Department of Energy contract DE-AC03077SF00515
} 
pulses. We have considered schemes that involve rotating wheels, bars or tapes that can be moved after damage. Of these, the rotating wheels seem the most promising technology.

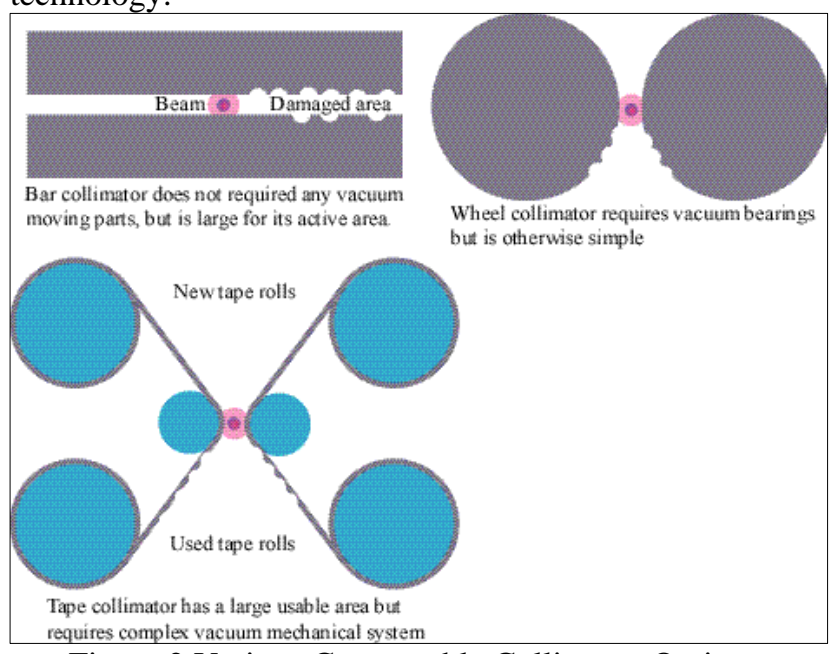

Figure 2 Various Consumable Collimator Options

\subsection{Repairable Collimators}

These are collimators where the jaws can be continuously repaired during operation, allowing their use under conditions where damage occurs on many or all beam pulses. We are developing a system where a low melting point liquid metal is frozen onto the surface of slowly turning metal drums. The solidified surface is rolled flat with smoothing rollers.

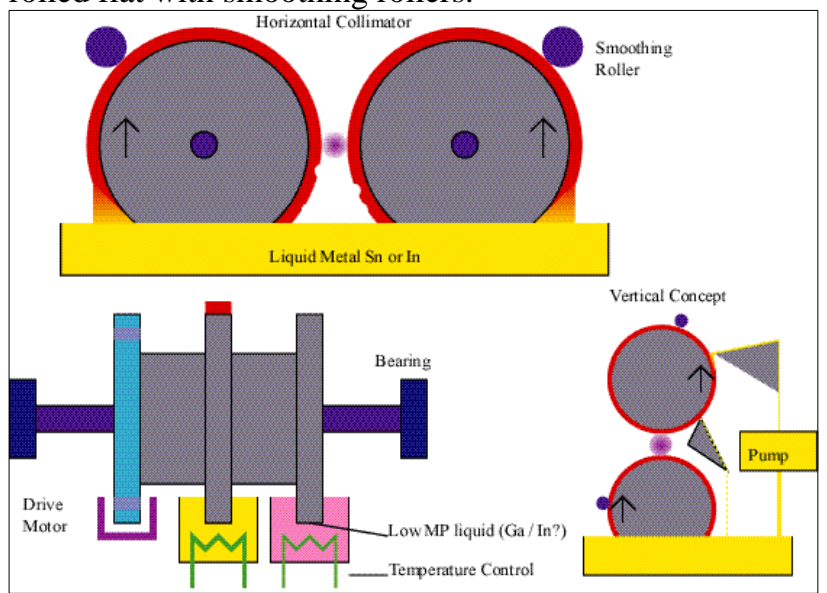

Figure 3 Liquid Indium or Tin is solidified onto rollers.

\section{R+D ON CONSUMABLE COLLIMATORS}

A $\mathrm{R}+\mathrm{D}$ program is underway to develop a prototype Consumable collimator. Test devices have been constructed for the critical components and detailed design work is proceeding on the final prototype.

\subsection{Collimation Surface Design}

There are two contradictory requirements on the collimation surface: The collimation depth should rise rapidly with radial distance from the beam line in order to provide effective collimation. The surface seen by the beam wake fields, on the other hand, must taper gradually into the beam to avoid emittance degradation. We are developing a system where a high $\mathrm{Z}$ material (probably Copper) is combined with a low $\mathrm{Z}$ material (probably Beryllium) to meet these requirements.

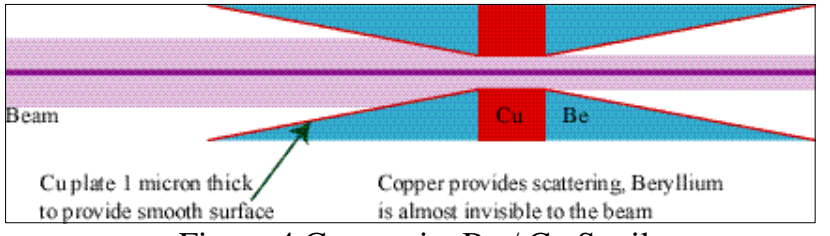

Figure 4 Composite $\mathrm{Be} / \mathrm{Cu}$ Spoiler

We have constructed a test sample consisting of a Copper plate brazed to a Beryllium plate. Both plates are polished, and then coated with a 1-micron layer of copper. A profile across the plate gave a surface roughness of $200 \mathrm{~nm}$ RMS, with a $2.5 \mu \mathrm{m}$ step at the junction between Beryllium and Copper. The roughness meets our spec, however the step is a factor of $\sim 2$ too large. The step may be reduced by replacing the Copper with a harder material such as Nickel, Molybdenum.

\subsection{Wheel Collimator Mechanical Design}

We have designed a system where the two main rollers are sprung onto two pairs of smaller guide rollers. The guide rollers act as a reference surface and eliminate alignment effects from expansion of the main rollers. The separation of the guide rollers can be changed, resulting in a change in the gap between the rollers.

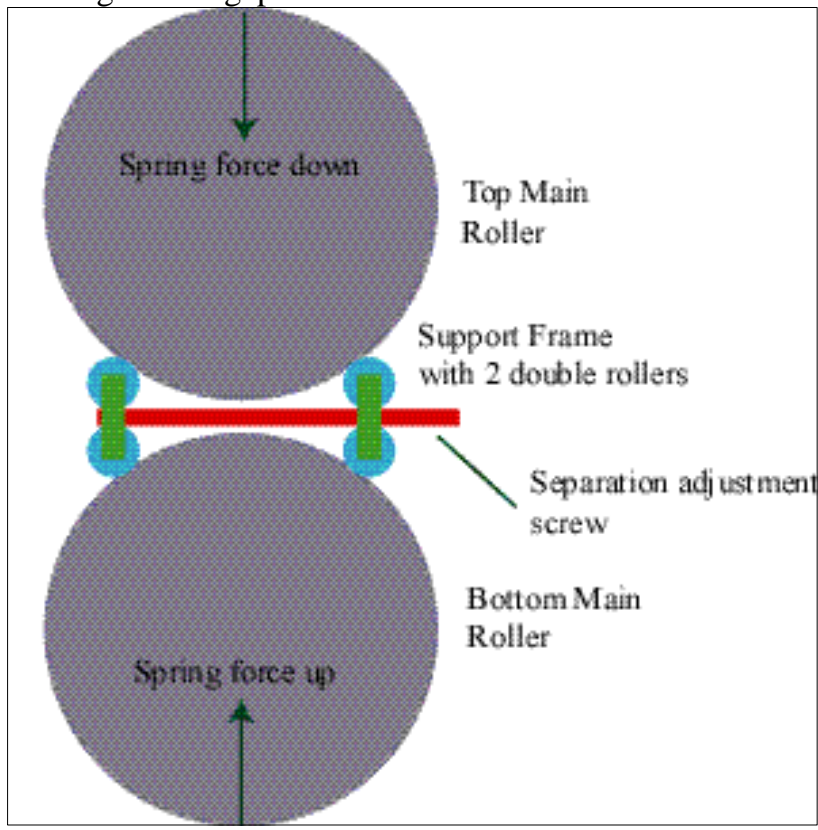

Figure 5 Rollers are referenced to a central support.

\subsection{Bearing Tests}

The bearings on the support frame were considered a possible technical issue. A 400 series stainless steel 
bearing of a type similar to that proposed for the collimator was operated in UHV at a force of 45 pounds, without lubrication for 3000 cycles at room temperature, and 9000 cycles at $125^{\circ} \mathrm{C}$. The bearings are required to operate for approximately 10,000 cycles at a load of approximately 10 pounds.

There was no measurable torque increase ( $25 \%$ experimental uncertainty) after the ambient temperature tests. The torque increased a factor of 2 after the high temperature tests, but was still acceptable.

\section{$4.4 R+D$ on Repairable Collimators}

We are developing a prototype for the solidifying metal collimator described in figure 3 . The primary technical issue is materials properties. A variety of materials combinations were tested in an inert Nitrogen or Argon environment

\subsection{Materials Options}

The materials search was restricted to elemental liquid metals in order to avoid problems with fractional crystallization during solidification. The only liquid metals with sufficiently low vapor pressure at their melting point are [2]

Table 2: NLC beam parameters in the Collimation Section (maximum values)

\begin{tabular}{llll}
\hline Material & $\begin{array}{c}\text { Melting } \\
\text { Point }\end{array}$ & $\begin{array}{c}\text { Vapor Pressure } \\
\text { at MP / } \\
\text { MP+100C }\end{array}$ & $\begin{array}{c}\text { Radiation } \\
\text { Length } \\
\text { cm }\end{array}$ \\
\hline $\mathrm{Li}$ & 180 & $10^{-10} / 10^{-7}$ & 150 \\
$\mathrm{Ga}$ & 30 & $<10^{-11} /<10^{-11}$ & 2.1 \\
$\mathrm{In}$ & 156 & $<10^{-11} /<10^{-11}$ & 1.2 \\
$\mathrm{Sn}$ & 231 & $<10^{-11} /<10^{-11}$ & 1.2 \\
\hline
\end{tabular}

Of these, $\mathrm{Li}$ was rejected due to its long radiation length and $\mathrm{Ga}$ was rejected due to its forming a brittle solid which could not be rolled flat after solidification.

Based on liquid metal corrosion data [3], a variety of inert materials was tested for use as the liquid metal container, and for the smoothing roller. $\mathrm{Al}_{2} \mathrm{O}_{3}$, Glassy Carbon, Tungsten and Beryllium were found to be resistant to molten Tin and Indium at the maximum test temperature of $800^{\circ} \mathrm{C}$ (Tungsten was tested up to $900^{\circ} \mathrm{C}$ ). Molybdenum and Niobium were moderately resistant.

The liquid metal must adhere to the substrate material, but must not corrode it, a difficult requirement due to the close relationship between corrosion and adhesion. The solution found was to heat the solid material in liquid metal at $800-900{ }^{\circ} \mathrm{C}$ for 24 hours to form a coating (through solution or intermetallic reactions). Then at low temperature (near the melting point) the liquid metal would wet the coated material repeatedly. The most successful combinations were liquid Tin with Molybdenum or Niobium.

Samples of substrate material coated at $800 \mathrm{C}$ were dipped in low temperature $(250 \mathrm{C})$ liquid tin which formed a thick $(1 \mathrm{~mm})$ coating. This coating was then rolled at room temperature to form a flat surface. The adherence between the solid Tin and the substrate was not broken by the rolling process. There was some sign of corrosion of the Molybdenum coating after 3 months in liquid tin at $270 \mathrm{C}$. Long term tests have not yet been done on Niobium.

\subsection{Repairable Collimator Test System}

A test system that will operate in moderate vacuum $\left(10^{-}\right.$ ${ }^{6}$ Torr) has been designed and is being constructed. It will use a Molybdenum or Niobium main roller, pre-treated in Tin at $900 \mathrm{C}$. The smoothing roller will be Molybdenum.

\section{SUMMARY}

The high beam energy density in the NLC requires the use of advanced collimator technology. A prototype consumable collimator, which can survive on the order of a thousand events of beam damage from errant pulses is being constructed. Component tests have demonstrated the most critical technologies for these systems. Work is also underway to develop a repairable collimator based on a continuously formed solidifying metal surface. This collimator could operate even if there were beam damage on every pulse. Materials tests for this system are underway, and a technology demonstration prototype is being constructed.

\section{REFERENCES}

1. Lin, Xintian E. , and Whittum, David H. "Image Current Heating on Metal Surfaces Due to Charged Bunches" SLAC Pub 8393 (2000).

2. O'Hanlon, John F. A Users guide to Vacuum Technology, New York, Hohn Wiley \& Sons, (1980), pp. 371-373.

3. Lyon, Richad N, "Liquid-Metals Handbook", Office of Naval Research, (1952) 